\title{
THE MEASURED ENERGY IMPACT OF INFILTRATION IN AN OUTDOOR TEST CELL
}

\author{
Mingsheng Liu and David E. Claridge \\ Energy Systems Laboratory \\ Texas A\&M University
}

\begin{abstract}
A B S T R A C T
The energy consumption calculation of house envelopes assumes that conduction heat loss is independent on air infiltration heat loss, and that energy consumption is the sum of these losses. Anderlind [1985], Liu [1987], and Claridge et al. [1989] showed this method can overestimate energy consumption substantially under steady-state conditions. Bailly [1987] and Anderson [1987] reported much smaller house energy consumption when the air flow was organized by mechanical systems. However, none of these studies quantified energy loss reduction under a variety of outdoor weather conditions. The energy performance was investigated in an outdoor test cell with different leakage configurations and air flow rates under both infiltration and exfiltration. It was found that the energy consumption was not only dependent on air flow rate, temperature differences, and solar radiation, but also on the air flow direction and the air leakage configuration. Infiltration could lead to a much lower heating energy consumption than that of exfiltration, and exfiltration could lead to a much lower cooling energy consumption than that of infiltration. The air infiltration energy consumption of a leaky house could be 9 times as high as that of a tight house even when the air flow rate was the same for both houses.
\end{abstract}

\section{N T RODU C T I O N}

The energy consumption calculation of house envelopes assumes that conduction heat loss is independent on air infiltration heat loss, and that energy consumption is the sum of these losses. Recent research showed this assumption could lead to substantial overestimation of energy consumption. Anderlind [1985] and Liu [1987] showed theoretically that an idealized diffuse wall might consume as little as 0 to $20 \%$ of designed air in filtration energy loss under steady-state conditions when the conduction energy consumption was calculated according to the design method. Claridge and Bhattacharyya [1989, $1990,1992]$ showed experimentally that the actual air infiltration energy consumption varied from $20 \%$ to $80 \%$ of the design value on an indoor test cell and frame insulation wall under steady-state conditions. The experiment found that air infiltration energy consumption was influenced by both the air flow rate and leakage configuration. These studies were limited to the scope of the indoor conditions and idealized model.
Bailly [1987] reported that a dynamic insulation house system (forcing air flow through a porous insulation layer) could save from $7 \%$ to $14 \%$ of heating energy for a winter season. Kohonen et al. [1987] studied the overall energy recovery effect of air infiltration on a house. They suggested a factor of 0.8 as a correction on the opaque envelope conduction heat loss for heating seasons to take account of heat loss reduction when the air infiltration was present. Andersson and Wadmark [1987] studied the OPTIMA (optimum) ceiling and roof defined as a house structure where air was sucked in through the ceiling insulation, then made to flow through the rooms to the crawl space, and finally was exhausted through the chimney in a single family house. They found that OPTIMA could recover most of the heat loss through the ceiling insulation, and provided good environmental conditions in the rooms. Although these studies were conducted on houses under outdoor conditions, all of them focused on the house model illustration. None of these studies quantified heat loss reduction under a variety of outdoor weather conditions. There was no suggestions given regarding the techniques of minimizing the energy loss in houses.

In order to investigate the effects of air flow rate, air flow direction, leakage configuration, and solar radiation on the house energy consumption under weather conditions, and subsequently to give suggestions of minimizing the energy consumptions in houses, an outdoor test cell was built, a measurement methodology was developed, and the energy performance (heat loss factor and energy savings) was measured over a two-year period for four air leakage configurations and different air flow rates. The test facility, methodology, and results are described in the following sections.

\section{E Q U I P M E N T}

The outdoor test cell, built in 1990 especially for the measurement of air infiltration heat recovery, was located at the Texas A\&M Riverside Campus. The cell was a 2.4 meter ( 8 feet) cube topped with a small attic. The walls were standard $2 \times 4$ frame construction with exterior plywood, R-11 insulation, and plywood. The ceiling and roof were built with plywood, R-19 insulation, an attic air space, plywood sheathing, and asphalt roofing. The schematic of the test cell is shown in Figure 1. 
There were two concentrated holes in the north wall (see Figure 2): hole "A", which was $10 \mathrm{~cm}$ (4 inches) in diameter, served as the fan outlet or inlet; hole "B", which was $5 \mathrm{~cm}$ ( 2 inches) in diameter, served as the concentrated flow path. The north wall also contained a $61 \mathrm{~cm}$ ( 24 inches) wide by $205 \mathrm{~cm}$ ( 80 inches) high door to simulate crack flow. The "door" construction was similar to the wall. Both the interior and exterior plywood panels of each wall have 8 "diffuse" holes ( 4 located 13 $\mathrm{cm}$ (5 inches) from the ceiling, 4 located $13 \mathrm{~cm}$ ( 5 inches) from the floor) $1 / 2$ inch in diameter and spaced equal distances across the wall.

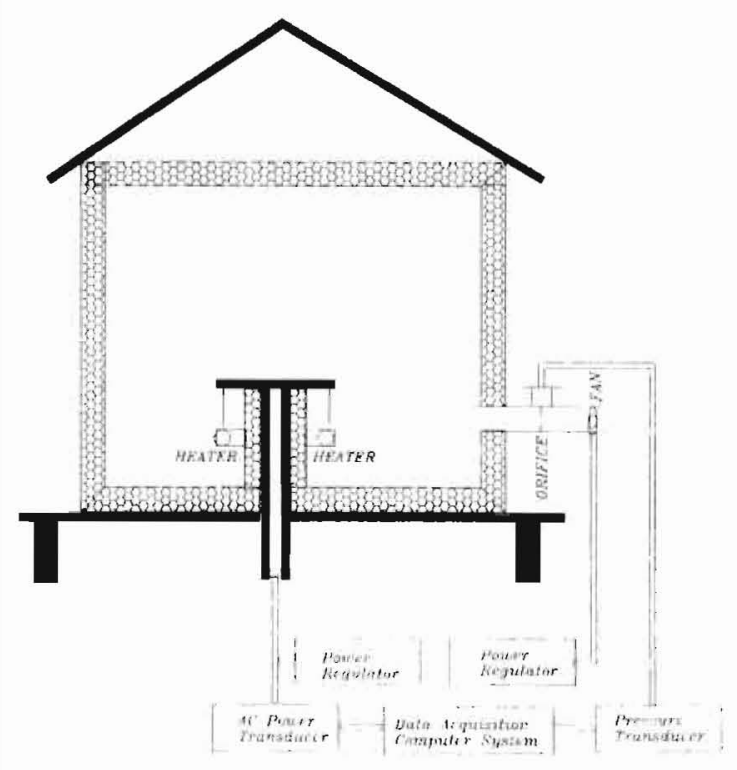

Figure 1: Schematic of the Test Cell

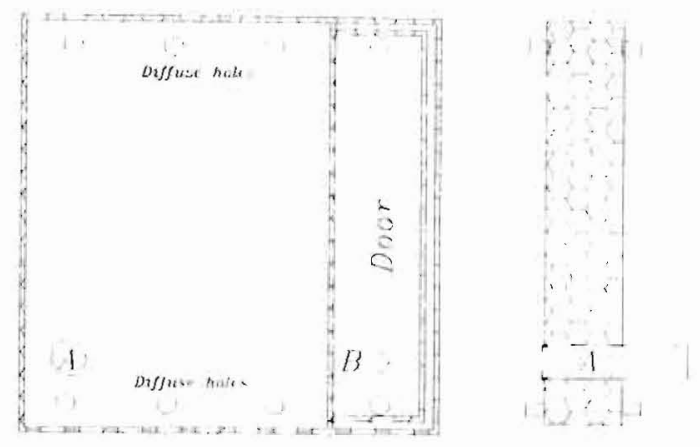

Figure 2: Schematic of the North Wall
Four leakage configurations were defined: (1) concentrated leakage (air introduced or exhausted through hole "A", hole "B" open, diffuse holes blocked, and the cracks sealed); (2) diffuse leakage (air introduced or exhausted through hole "A", hole "B" closed, "diffuse" holes blocked, and "cracks" sealed); (3) quasi-diffuse leakage (air introduced or exhausted through hole "A", hole "B" closed, "diffuse" holes open, and "cracks" sealed); and (4) large crack leakage (air introduced or exhausted through hole "A", hole "B" closed, "diffuse" holes blocked, and "cracks" unsealed).

The test cell mass temperatures were monitored by 220 thermocouples ( 40 in each wall and floor, and 20 in the ceiling), the test cell air temperature by 12 thermocouples, which were uniformly distributed inside the cell, and the outside temperature by two well shielded thermocouples located north of the cell. The horizontal solar radiation was measured by an on-site pyranometer. and the air flow rate was controlled by a fan with the flow rate measured by an orifice. The power was supplied by a heater with an adjustable range of 0 to $500 \mathrm{~W}$ and was measured by a power transducer. The pressures across the walls, due to both natural force and mechanical force, were measured separately by 5 pressure transducers ( four for natural force, one for mechanical force).

A data acquisition system was used to couple the sensors to a computer, where the signals were sampled, precalculated, and finally recorded on a hard disk. All of the signals were sampled, converted to necessary engineering units every 10 seconds, and 10 minute time average values were recorded in LOTUS format.

A special control room was built to serve the data acquisition system, the computer, the pressure sensors, and the power regulator. The control room was conditioned to provide a suitable environment for the test facilities.

\section{METHODOLOG Y}

The tests consisted of three phases: determination of the solar contribution, determination of the conduction heat loss factor, and normal tests.

The solar contribution was defined as the rise in cell temperature due to unit solar radiation on the cell when no air infiltration was present. It was determined from a seven-day test with no heat input with the cell tightly caulked from the following expression:

$$
\delta \mathrm{T}=\frac{\sum_{\mathrm{i}=1}^{k} \mathrm{~T}_{\text {cell }}(\mathrm{i})-\mathrm{T}_{\text {out }}(\mathrm{i})}{\sum_{\mathrm{i}=1}^{\mathrm{k}} \operatorname{Solar}(\mathrm{i})}
$$


where:

$$
\begin{aligned}
& \delta \mathrm{T}=\text { solar contribution to the cell temperature } \\
& \left({ }^{0} \mathrm{C} / \mathrm{W} / \mathrm{m}^{2}\right) \\
& \mathrm{T}_{\text {cell }}=\text { test cell air temperature }\left({ }^{\circ} \mathrm{C}\right) \\
& \mathrm{T}_{\text {out }}=\text { ambient air temperature }\left({ }^{\circ} \mathrm{C}\right) \\
& \text { Solar = equivalent solar radiation on the cell } \\
& \left(\mathrm{W} / \mathrm{m}^{2}\right) \text { defined as the ratio of the }
\end{aligned}
$$

The conduction heat loss factor $\mathrm{UA}_{\mathrm{O}}$ was defined as the heat loss rate of the cell with unit temperature difference between cell and ambient air when air infiltration was not present. It was calculated using the following formula for a week long test with a constant heat input to the test cell:

$$
U A_{O}=\frac{\sum_{i=1}^{k} q(i)+U A_{0} \sum_{i=1}^{k} \operatorname{Solar}(i) \delta T}{\sum_{i=1}^{k}\left[T_{\text {cell }}(i)-T_{\text {out }}(i)\right]}
$$

where:

$$
\begin{aligned}
& \mathrm{q} \quad=\text { heat input }(\mathrm{W}) \\
& \mathrm{UA}_{\mathrm{O}} \quad=\text { conduction heat loss factor }\left(\mathrm{W} /{ }^{\circ} \mathrm{C}\right) \\
& \text { Other symbols were defined in Equation (1). }
\end{aligned}
$$

A constant heat input and air flow rate were imposed for each normal test. Then the heat loss factor of the test cell was calculated by the following formula for a selected period:

$$
U A=\frac{\sum_{i=1}^{k} q(i)}{\sum_{i=1}^{k} T_{\text {cell }}(i)-T_{\text {out }}(i)-\operatorname{Solar}(i) \delta T}
$$

where:

$\mathrm{UA}=$ heat loss factor (conduction plus infiltration) of the test cell $\left(\mathrm{W} /{ }^{\circ} \mathrm{C}\right)$

Other symbols have been defined in Equation (1).

It should be pointed out that a constant air flow rate was required in order to warrant a linear process [Liu \& Claridge 1992].

The infiltration heat exchange effectiveness (IHEE) and energy saving ratio were defined and calculated by the formula:

$\mathrm{IHEE}=\frac{\mathrm{UA}_{\mathrm{Classical}}-\mathrm{UA}}{\mathrm{MCp}}$
$\beta=\frac{\mathrm{UA}_{\text {classical }}-\mathrm{UA}}{\mathrm{UA}_{\text {classical }}}$

where:

$$
\begin{aligned}
& \mathrm{UA}_{\text {classical }}=\mathrm{UA}_{\mathrm{O}}+\mathrm{MCp} \text {, heat loss factor } \\
& \text { alculated based on the design } \\
& \text { method } \\
& \mathrm{M} \text { = air infiltration/exfiltration rate } \\
& (\mathrm{Kg} / \mathrm{s}) \\
& \mathrm{Cp} \quad=\text { specific heat capacity of air } \\
& \left(\mathrm{J} / \mathrm{Kg}{ }^{\circ} \mathrm{C}\right) \text {. }
\end{aligned}
$$

The time period was chosen such that if the period received a contribution from the parameters outside the period, then the parameters within the period contributed to the outside of the period by the same amount. This principle made possible to use period average parameters to estimate the energy performance if the thermal storages were same at both the beginning and the ending. It was realized by the following rules: (1) both the beginning and the ending time should be between 11:00 pm to $6: 00 \mathrm{am}$ in order to restrict the solar radiation and its contribution within the period; (2) the test cell mass temperature difference between beginning and ending of the period was less than $0.1^{\circ} \mathrm{C}$, thus eliminating thermal storage influence; and (3) the period moving-average ambient temperature and test cell mass temperatures should be constant from time index $\mathrm{l}$ to $\mathrm{k}$, where $\mathrm{k}$ is the time index corresponding to 4 hours, thus restricting the temperatures and their contributions within the same period. These rules were developed based on transfer function theory [Liu 1992].

\section{R E S U L T S}

Liu's theoretical analysis [1987] showed that IHEE of a idealized diffuse wall could be expressed by the following formula when both infiltration and conduction heat losses were present:

$$
\mathrm{IHEE}=\frac{\exp (\alpha)-(1+\alpha)}{\alpha(\exp (\alpha)-1)}
$$

(6)

$$
\begin{aligned}
& \text { where: } \\
& \begin{array}{ll}
\alpha & =\left(\frac{\mathrm{MC}}{\mathrm{UA}_{\mathrm{O}}}\right) \text { non-dimensional air flow rate } \\
\mathrm{M} & =\text { air flow rate }(\mathrm{Kg} / \mathrm{s}) \\
\mathrm{Cp} & =\text { specific heat of air }\left(\mathrm{J} / \mathrm{Kg}^{\circ} \mathrm{C}\right) \\
\mathrm{UA}_{\mathrm{O}} & =\text { conduction heat loss factor }\left(\mathrm{W} /{ }^{\circ} \mathrm{C}\right) .
\end{array}
\end{aligned}
$$

The infiltration heat exchange effectiveness and the heat loss factor were measured for four air leakage configurations and different air flow rates under both infiltration and exfiltration conditions from summer 1990 to autumn 1991 on the outdoor test cell. The discussion of IHEE and general energy consideration is given as follows: 
Both the measured and the diffuse wall model (equation 6) IHEEs are shown in Figures 3, 4, and 5 as a function of a non-dimensional air flow rate. The results show that the IHEE varied from 0.52 to 0.4 ( $\alpha$ from 0.4 to 1.4 ) for the diffuse leakage configuration, from 0.35 to 0.32 ( $\alpha$ from 0.7 to 1.4) for the concentrated leakage configuration, and from 0.3 to 0.25 ( $\alpha$ from 0.45 to 1.25 ) for the crack leakage configuration when air leaked in through the test cell envelope and was exhausted by a fan. The IHEE varied from 0.4 to 0.3 ( $\alpha$ from 0.6 to 1.1 ) for the diffuse leakage configuration, from 0.3 to -0.15 ( $\alpha$ from 0.7 to 1.4) for the concentrated leakage configuration, and from -0.05 to -0.1 ( $\alpha$ from 0.5 to 1.3) for the crack leakage configuration when the air was supplied to the test cell by the fan and leaked out through the test cell envelope. These numbers showed that the IHEE was dependent on the leakage configuration, air flow rate, and air flow direction.

The negative IHEE values in the cases of crack exfiltration and concentrated exfiltration might be caused by: (1) solar contribution (exfiltration could reject more solar energy to the outside), (2) leakage configuration change (the pressurization of the room might enlarge the cracks surrounding the door with time), or (3) measurement error (the heat recovery was relative smaller in these cases).

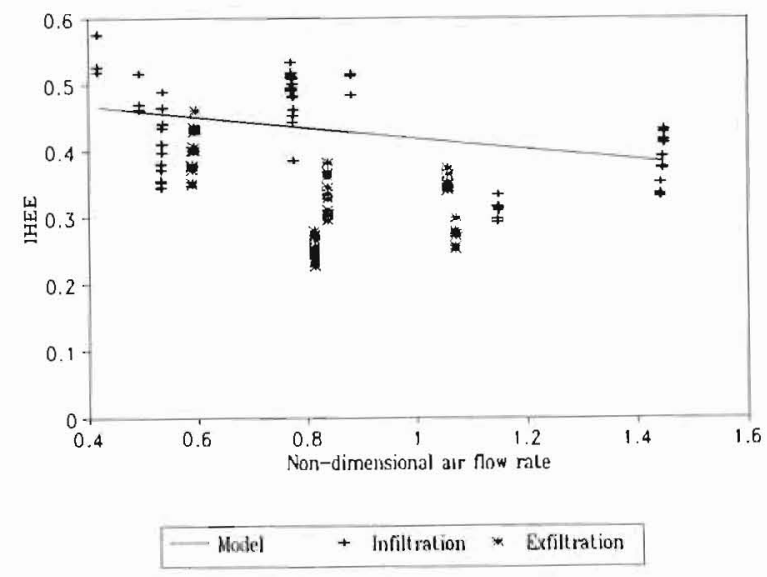

Figure 3: IHEE for the Diffuse Leakage Configuration (Model - Steady-state diffuse wall model)

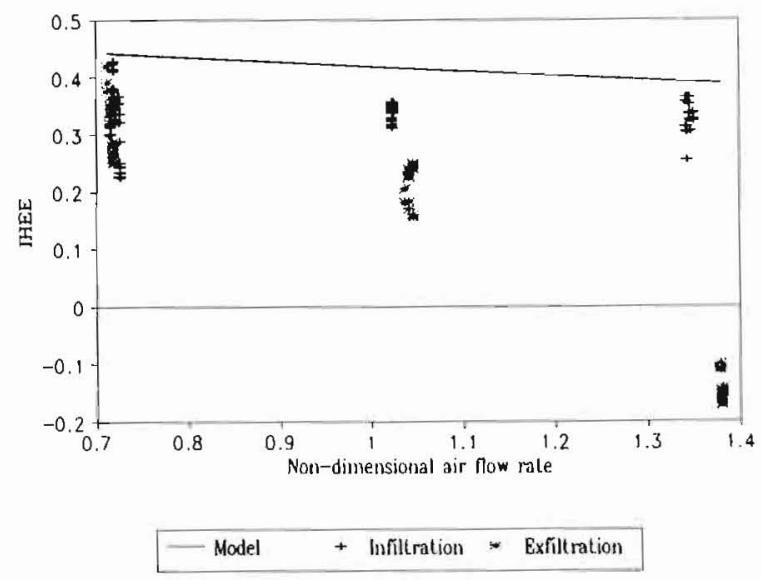

Figure 4: IHEE for the Concentrated Leakage Configuration

(Model - Steady-state diffuse wall model)

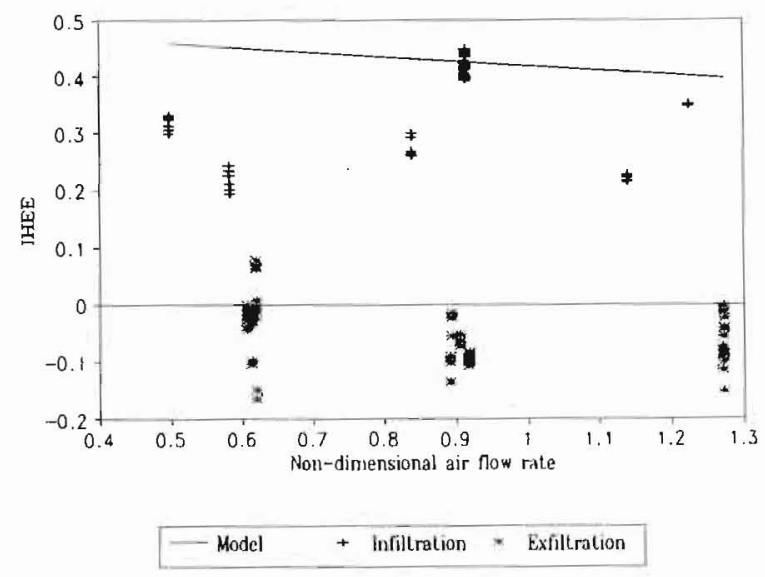

Figure 5: IHEE for the Crack Leakage Configuration (Model - Steady-state diffuse wall model)

\section{Effects of Leakage Configuration on I H E E}

The leakage configurations had a significant influence on the IHEE. The IHEE values $(0.52$ to 0.4 for infiltration, and 0.4 to 0.3 for exfiltration) of the diffuse leakage configuration were much higher than those $(0.35$ to -0.15$)$ of both the concentrated and crack leakage configurations because the uniform diffuse flow had higher energy exchange effectiveness if the wall was regarded as a heat exchanger. This result was consistent with the early results from the indoor cell measurement. 
If a house was constructed to have such a tight structure that the air leaked in through half of the building envelope and out through another half diffusely, the house would be likely to have an IHEE from 0.92 to 0.7 under weather conditions similar to those of the tests. If a house was constructed such as in the crack leakage configuration, it would be likely to have an IHEE from 0.1 to 0 . Obviously, a leaky house could consume as much as 9 times the air infiltration energy as a tight house.

\section{Effects of Air Flow Rate on IHEE}

The measurement results showed that the IHEE decreased with the air flow rate in all the leakage configurations, and the slope was very close to the slope of the IHEE from the idealized diffuse wall steady-state model. This result was also consistent with that discovered from the steady-state test conducted in the indoor test cell.

\section{Effect of Air Flow Direction on I H E E}

The measurement results showed that the infiltration had a higher IHEE than those of exfiltration when the test cell was heated to a higher temperature than outside. The diffuse leakage configuration had infiltrating IHEE values in rage of 0.52 to 0.4 and exfiltrating IHEE values in the range of 0.4 to 0.3 . The concentrated leakage configuration had infiltrating IHEE values in the range of 0.35 to 0.32 and exfiltrating IHEE values in the range of 0.3 to -0.15 . The crack leakage configuration had the infiltrating IHEE values in the range of 0.3 to 0.25 and exfiltrating IHEE values in the range of -0.05 to -0.15 . These IHEE differences reflected the different solar energy contributions under infiltration and exfiltration conditions. Under infiltration conditions, the air carried more solar energy captured by the wall surface into the cell. However, under exfiltration conditions, the air rejected more solar energy to the outside. This discovery inferred that exfiltration should result in a higher IHEE for cooling because the exfiltration could reject more solar energy to the outside and subsequently reduce the cooling energy consumption.

If a house had an exfiltration rather than an infiltration in the winter season, it was inferred that a "diffuse house" might consume $20 \%$ more, a "concentrated house" might consume $15 \%$ more, and a "crack leakage house" might consume $40 \%$ more air infiltration energy according to the measurement results. If exfiltration was used in a house for the summer season, extra energy consumption would be expected according to the measurement results.

\section{Effects of Solar Radiation on I H E E}

The IHEEs of the quasi-diffuse leakage configuration are shown as a function of both equivalent solar radiation and air flow rate in Figure 5-8. The IHEE responding to the zero solar radiation was measured for a single night period. The IHEE surface was created by using the Graphic package "Surfer". The results showed that the IHEE decreased dramatically with solar radiation, and the IHEE decreased slightly with the air flow rate. However, the effects of the air flow on the lHEE increased with the solar radiation. The relationship of the solar radiation and the IHEE was worth investigating further because this test showed promising benefits.

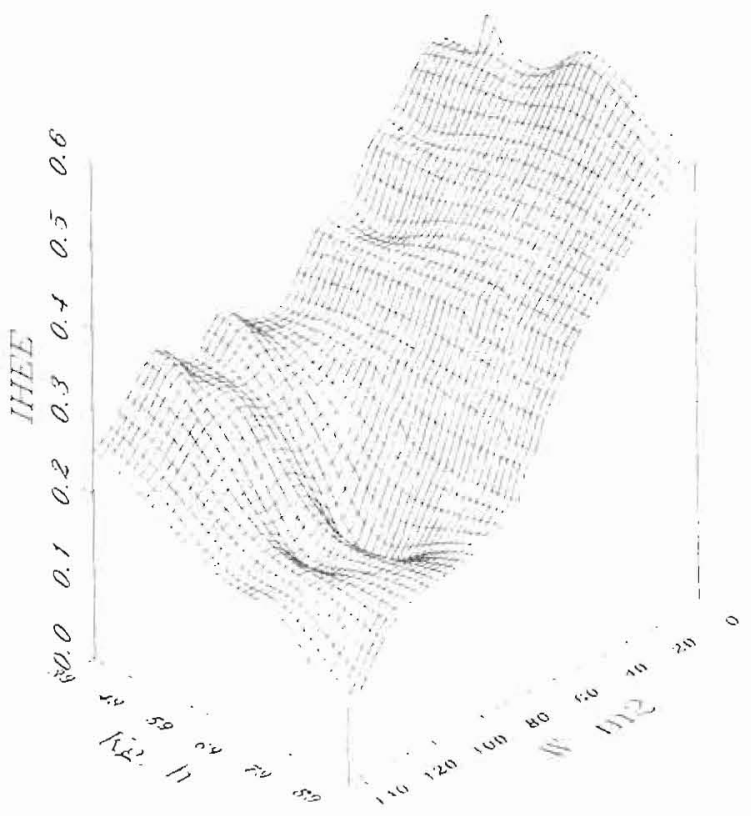

Figure 6: IHEE vs Equivalent Solar Radiation and Air Infiltration Rate for Quasi-Diffuse Leakage Exfiltration Configuration

(Test Cell Was Pressurized by Fan) 


\section{Energy Saving Ratio}

The heat energy savings ratio gave another view of the air infiltration heat recovery. The results are shown in Figures 7, 8, and 9. Observation indicated that the total energy savings was about $15 \%$ to $25 \%$ for the diffuse infiltration, $10 \%$ to $20 \%$ for the diffuse exfiltration, $10 \%$ for the crack infiltration, $-10 \%$ for the crack exfiltration, $15 \%$ for the concentration infiltration, and $10 \%$ for the concentration exfiltration. These demonstrated clearly that the energy saving ratio was dependent on the leakage configuration, air flow rate, air flow direction, and the solar radiation. The diffuse structure saved more energy than other two structures. The infiltration saved more energy than exfiltration for this heating situation, because the infiltration carried more solar energy into the test cell. The energy saving ratio increased with the air flow rate, because the part of air infiltration energy consumption increased with air flow rate. Although the IHEE decreased slightly with the air flow rate, the total energy savings (IHEE $C_{\mathrm{p}} \mathrm{M}$ ) increased with the air flow rate.

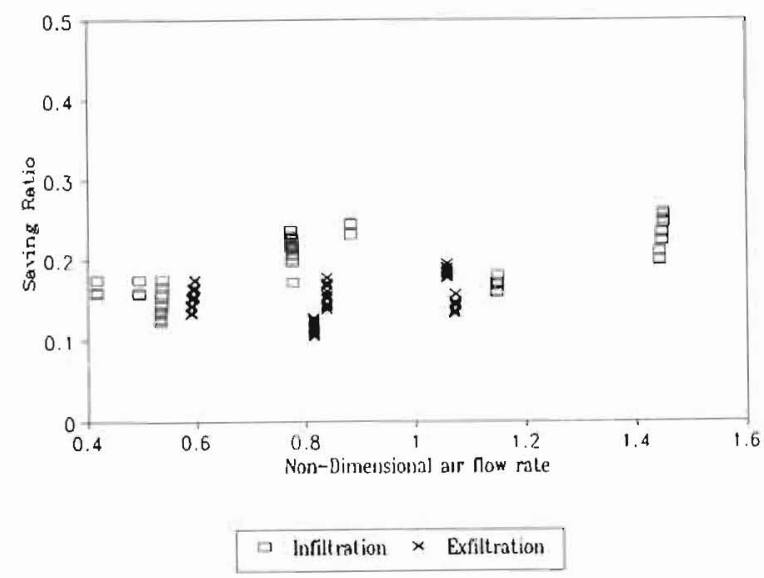

Figure 7: Total Energy Saving Ratio for Diffuse Leakage Configuration

From these results, it was inferred that if the test cell had diffuse infiltration over half of the envelope and diffuse exfiltration over the other, the energy saving ratio could be as high as $35 \%$. However, the test cell might have a energy saving ratio less than zero if air leaked in through big cracks in the walls where there was no solar radiation and leaked out through sunny walls, such as in the case of the crack leakage configuration tested in the measurement. Obviously, houses could have very different energy consumptions due to the air infiltration configurations even if the houses had same geometrical profile, and the same level of insulation under the same weather conditions.

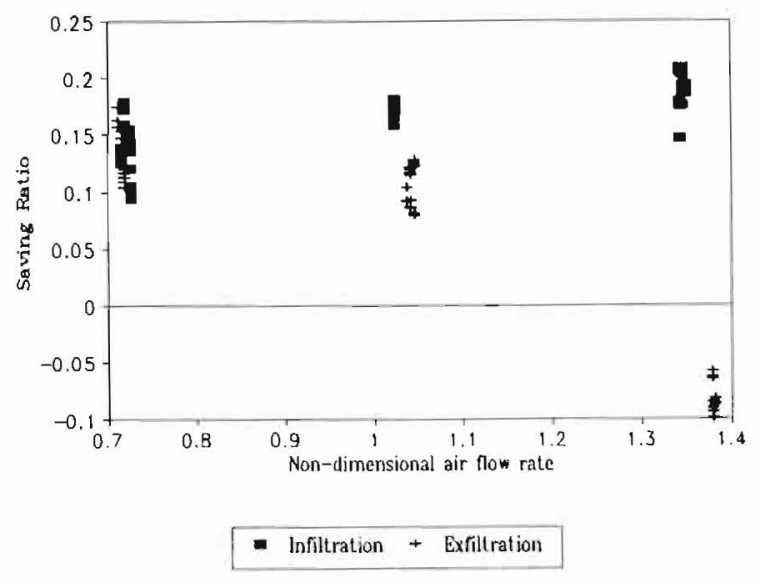

Figure 8: Total Energy Saving Ratio for Concentrated Leakage Configuration

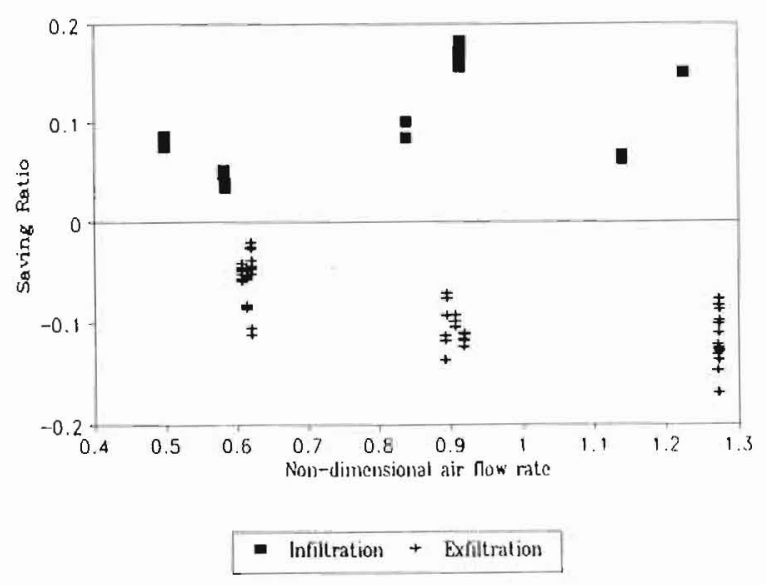

Figure 9: Total Energy Saving Ratio for Crack Leakage Configuration

\section{CON C L US I O N}

Air infiltration heat recovery was investigated experimentally in an outdoor test cell with four leakage configurations and different air flow rates under both infiltration and exfiltration conditions. The air infiltration/exfiltration rate and the heat input were controlled to be constant for each test.

The experiment revealed that the energy performance was strongly dependent on the leakage configuration, air flow direction, and solar radiation under real weather conditions. The diffuse leakage configuration had a higher IHEE than either concentrated or crack leakage configuration, and the IHEE decreased with the air flow rate. However, the energy saving ratio increased with the air flow rate. The infiltration could result in a higher 
IHEE value for heating and exfiltration for cooling because the solar energy contribution was substantially influenced by the air infiltration direction.

It was inferred from the measurements that a leaky house could consume as much as 9 times the air infiltration energy as a tight house, and that house energy consumption could be reduced up to $35 \%$ if the air infiltration was organized by a fan.

It is important to point out that the dependence of IHEE on solar radiation should be further investigated, and that a real house test should be carried out eventually to confirm the energy savings detected in our test cell.

\section{A C K N OW LED GEMENTS}

This work was supported by the Texas Higher Education Coordinating Board under Energy Research and Application Program (ERAP) project $\# 227$.

\section{R E F E R E N C ES}

Anderlind, G., 1985, "Energy Consumption Due to Air Infiltration," Proceedings of the 3rd ASHRAE/DOE/BTECC Conference on Thermal Performance of the Exterior Envelopes of Buildings, Clearwater Beach, FL, 1985, pp. 201-208.

Andersson K. A. and Wadmark T., 1987, "Use of Ventilation and Insulation in Single Family Houses for Thermal Comfort, Energy Conservation and Protection Against Moisture, Dust and Radon, the OPTIMA Concept," Proceedings of the 3rd International Congress on Building Energy Management ICBEM'87, Vol. 3, Lausanne, Switzerland, October, 1987.

Bailly, N.R., 1987, "Dynamic Insulation Systems and Energy Conservation in Buildings," ASHRAE Transactions, Vol. 93, 1987, part 1, pp. 447-466.

Bhattacharyya, S. and Claridge, D. E., 1992, "The Energy lmpact of Air Leakage Through Insulated Wall," To be published in Solar Engineering 1992.

Claridge, D.E. and Bhattacharyya, S., 1990, "The Measured Energy Impact of Infiltration in a Test Cell," Journal of Solar Energy Engineering, Vol. 112, 1990, pp. 132-139.

Kohonen, R., Tech, D., and Wirtanen, M., 1987, " Thermal Coupling of Leakage Flows and Heating Load of Buildings," ASHRAE Transactions, Vol. 93, Part 2, 1987, pp2303-2318.
Liu Mingsheng, 1987, "Thermal Techniques in Buildings," Harbin Archilectural and Civil Engineering Institute Press, 1987. Harbin.

Liu, Mingsheng, 1992, "Study of Air Infiltration Energy Consumption," Ph.D Dissertation, Texas A\&M University, August, 1992.

Liu Mingsheng \& Claridge D. E., 1992, "The Measured Impact of Air Infiltration Under Dynamic Conditions," Proceedings of 8th Symposium on Improving Building System in Hot and Humid Climates, 1992, Dallas, TX. 